\title{
積層型超磁歪アクチュエータに関する研究*
}

\author{
汇田 弘 ${ }^{* *} \quad$ 大村悦二** 濱田隆治*** 堀江 明 $^{\dagger}$
}

\section{Giant Magnetostriction Actuator of Laminated Plate Type}

\author{
Hiroshi EDA , Etsuji OHMURA, Ryuji HAMADA and Akira HORIE
}

\begin{abstract}
Vibration actuators with laminated giant-magnetostriction-materials are stable in the magnetic field of high frequency by reason of less eddy current loss, comparing with conventional actuators with giant magnetostriction rod. A simple actuator of laminated type was produced as an experiment, where a thin slice of giant magnetostriction material was stuck on a metal thin plate. As the first step, the static characteristics of the present actuator was investigated. The displacement characteristics of the present actuator and stress distribution in the giant magnetostriction material were analyzed theoretically and compared with the experimental results. The influence of the adhesives for laminating the two thin plates was also investigated theoretically and experimentally, and validity of the present theory is confirmed. There is an optimum combination of the thickness of giant magnetostriction plate and one of the base metal to maximize the displacement of the actuator.
\end{abstract}

Key Words : Giant magnetostriction, Actuator, Laminating, Displacement, Stress, Adhesives

\section{1. 瑹言}

超磁歪材料は，従来の磁歪材に比べて変位が100〜1000倍, 出 力も10倍以上大きい(1)。このため特性に適したアクチュエー夕 やデバイスへの適用が進められている(2) (3)，ところで，この 材料は，高周波数で作動させようとすると，ジュール熱を発生 し，ある高周波数に至るとすべて熱に変換される．そこで, 高 周波数振動子として使用する場合，超磁歪材の抵抗 $\rho$, 比透磁 率 $\mu_{s}$ ，材料直径 Dで決まる臨界周波数 $f_{c}$ ～以内に設計する必 要がある(1)．この問題を解決する一つの方法は材料の薄板化や 薄膜による積層型超磁歪アクチュエータの高周波数化である.

ところで, 薄板化による積層は大部分が接着剂で接合される ため接着応力が残留し，超磁歪材料特有のジャンプ現象に影響 を及ぼし，機械的設計予荷重に接着残留応力が重盢さた状態と なる。

本研究は，薄板化した超磁歪材料と薄い基板で積層化したア クチュエー夕を作成して，その変位（たわみ），磁歪材に働く 応力の理論解析を行った，接着剤の影響を考虑し，実験と比較 してそれらの妥当性, 有効性を検討した結果, 積首型超磁歪ア クチュエー夕設計の一助となる結論を得ることができたので， 以下に報告する。

\footnotetext{
* 原稿受付 平成 6 年 11 月 29 日

** 正会員 荻城大学工学部 (日立市中成沢町 4-12-1)

*** 正会員 茨城大学工学部 (現, (株) 日立設備工業 : 日立市石名坂 1-12-22)

†茨城大学大学院 (現, (株) ニュン; 東京都品川区西大井 1-6-3）
}

\section{2. 理詥解析}

\section{1 アクチュエータの変位}

Fig1に示すような超磁歪材料を基板に接着した，積層型超磁 歪アクチュエータを考える．図において，上側を基板，下側を 超磁歪材料とし，基板の磁歪を 0 ，超磁歪材料の磁歪を $\lambda_{2}$ と する. そのときの境界面の $x$ 軸方向の変位 $u_{1}(x), u_{2}(x)$ は, 次式のように表される(4).

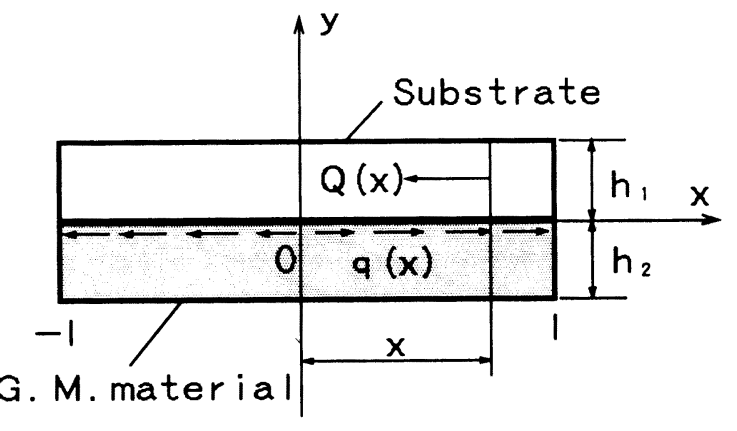

Fig. 1 A schematic of giant magnetostriction actuator GMA with laminated plate type.

$u_{1}(x)=-\frac{1-\nu_{1}{ }^{2}}{b E_{1} h_{1}} \int_{0}^{x} Q\langle\xi\rangle d \xi+\kappa_{1} q(x)+\frac{h_{1}}{2} \int_{0}^{x} \frac{d \xi}{\rho(\xi)}$ 


$$
\begin{aligned}
u_{2}(x)=\lambda_{2} x & +\frac{1-\nu_{2}^{2}}{b E_{2} h_{2}} \int_{0}^{x} Q\langle\xi) d \xi \\
& -\kappa_{2} q(x)-\frac{h_{2}}{2} \int_{0}^{x} \frac{d \xi}{\rho(\xi)}
\end{aligned}
$$

ここで, $b$ は板の幅, $E$ は弾性係数, $h$ は板厚, $\nu$ はポアソン比である. 添字1，2は，それぞれ基板と超磁歪材料 の物理量であることを表す．また， $\rho(x)$ は

曲率半径, $q(x)$ は単位長さ当たりのせん断力, $\kappa$ は界面のコ ンプライアンスで,

$$
\kappa_{i}=\frac{2\left(1+\nu_{i}\right) h_{i}}{3 b E_{i}} \quad(i=1,2)
$$

である.また， $Q(x)$ は板の断面に働く力である.

$$
Q(x)=\int_{-1}^{x} q(\xi) d \xi
$$

式(2)において，第 1 項は磁歪による変位，第 2 項は断面に働 く力 $Q(x)$ による変位, 第 3 項はせん断力 $q(x)$ による変位, 第 4 項は曲がりによる変位である．式(1)についても同様である.

いま，境界面では $u_{1}(x)=u_{2}(x)$ であるから，

$$
\begin{aligned}
& \kappa q(x)-\left(\frac{1-\nu_{1}{ }^{2}}{E_{1} h_{1}}+\frac{1-\nu_{2}{ }^{2}}{E_{2} h_{2}}\right) \int_{0}^{x} Q\langle\xi\rangle d \xi \\
& +\frac{b h}{2} \int_{0}^{x} \frac{d \xi}{\rho(\xi)}=b \lambda_{2} x
\end{aligned}
$$

を得る。ただし

$$
h=h_{1}+h_{2}, \kappa=b\left(\kappa_{1}+\kappa_{2}\right)
$$

とおいた。

一方, 曲げ剛性を

$$
D_{i}=\frac{E_{i} h_{i}{ }^{2}}{12\left(1-\nu_{i}{ }^{2}\right)} \quad(i=1,2)
$$

とすれば, 曲げモーメント

$$
M_{i}(x)=\frac{b D_{i}}{\rho(x)} \quad\langle i=1,2\rangle
$$

に関する平衡方程式

$$
M_{1}(x)+M_{2}(x)+\frac{h}{2} Q\langle x\rangle=0
$$

から

$$
\frac{1}{\rho(x)}=-\frac{h}{2 b D} Q(x)
$$

を得る.ここで, $D=D_{1}+D_{2}$ とおいた. 式(7)を式(5)に代入 すると，

$$
q(x)-k^{2} \int_{0}^{x} \int_{-1}^{\xi} q\left(\xi^{\prime}\right) d \xi^{\prime} d \xi=b \frac{\lambda_{2}}{\kappa} x
$$

を得る、ただし

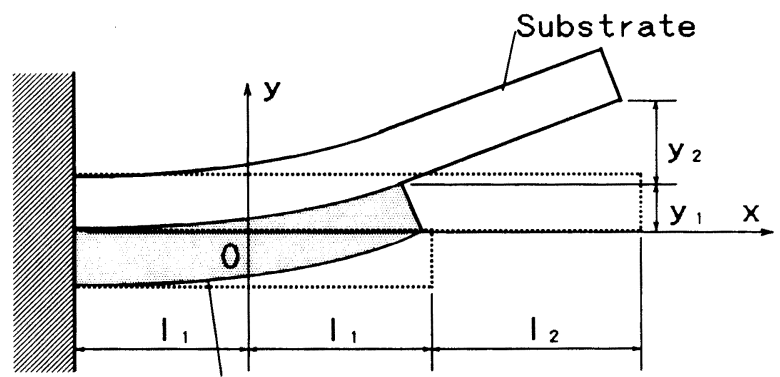

G. M. material

Fig2 Deformation of GMA formed by different length of laminated plate.

$$
k^{2}=\frac{r}{\kappa}, \quad r=\frac{1}{12}\left(\frac{h_{1}^{2}}{D_{1}}+\frac{h_{2}^{2}}{D_{2}}+\frac{3 h^{2}}{D}\right)
$$

である.

境界条件 $q(0)=0, Q(l)=0$ を満たす式(8)の解は

$$
q(x)=\frac{b \lambda_{2} \sinh k x}{k \kappa \cosh k l}
$$

であり, 式(4)より

$$
Q(x)=-\frac{b \lambda_{2}}{r}\left(1-\frac{\cosh k x}{\cosh k l}\right)
$$

となる。したがって, 式(7)より，微分方程式

$$
\frac{d^{2} y}{d x^{2}}=\frac{1}{\rho(x)}=\frac{h \lambda_{2}}{2 r D}\left(1-\frac{\cosh k x}{\cosh k l}\right)
$$

が得られる。ここで，y は $y$ 軸方向の変位である．

本研究では，後述するように, Fig2ような長さの異なる積首 板からなるアクチュエー夕を取り扱う。この場合，式(11)は

$$
\frac{d^{2} y}{d x^{2}}=\frac{h \lambda_{2}}{2 r D}\left(1-\frac{\cosh k x}{\cosh k l_{1}}\right)
$$

となる。境界条件

$$
\left.y\right|_{x=-l_{1}}=0,\left.\quad \frac{d y}{d x}\right|_{x=-l,}=0
$$

を満たす式(12)の解は

$y=\frac{h \lambda_{2}}{2 r D}\left[\left(\frac{l_{1}+x}{2}-\frac{1}{k}\right)\left(l_{1}+x\right)-\frac{\cosh k x}{k^{2} \cosh k l_{1}}+\frac{1}{k^{2}}\right]$

であり, $x=l 1$ における変位は，

$$
y_{1}=\frac{h l_{1} \lambda_{2}}{r D}\left(l_{1}-\frac{1}{k}\right)
$$

となる． $x=l_{1}+l_{2}$ における直線部分の変位は

$$
y_{2}=\left.\frac{d y}{d x}\right|_{x=l_{1}} l_{2}=\frac{h \lambda_{2}}{r D}\left(l_{1}-\frac{1}{k}\right) l_{2}
$$

であるから， $x=l_{1}+l_{2}$ における全変位は，結局

$$
y_{\text {total }}=y_{1}+y_{2}=\frac{h \lambda_{2}}{r D}\left(l_{1}-\frac{1}{k}\right)\left(l_{1}+l_{2}\right)
$$

となり, 変位 $y_{\mathrm{tota}} \mid$ は磁歪 $\lambda_{2}$ に比例する。逆に，変位 $y_{\text {total }}$ がわかれば, 式(17)から磁歪 $\lambda_{2}$ が求まる.

また，界面のひずみ $\varepsilon(x$ は，式(2), (10), (11)より

$$
\begin{aligned}
\varepsilon(x) & =\frac{d u_{2}(x)}{d x} \\
= & \lambda_{2}\left[1-\frac{1}{r}\left(\frac{1-\nu_{2}{ }^{2}}{E_{2} h_{2}}+\frac{h h_{2}}{4 D}\right)\left(1-\frac{\cosh k x}{\cosh k l}\right)\right. \\
& \left.-\frac{b \kappa_{2} \cosh k x}{\kappa \cosh k l}\right]
\end{aligned}
$$

であるから， $x=0$ における界面のひずみは

$$
\begin{gathered}
\varepsilon=\varepsilon\langle 0\rangle=\lambda_{2}\left[1-\frac{1}{\gamma}\left(\frac{1-\nu_{2}{ }^{2}}{E_{2} h_{2}}+\frac{h h_{2}}{4 D}\right)\left(1-\frac{1}{\cosh k l}\right)\right. \\
\left.-\frac{b \kappa_{2}}{\kappa \cosh k l}\right]
\end{gathered}
$$

よって， $x=0$ における磁歪材表面のひずみ $\varepsilon$ 。は

$$
\begin{aligned}
\varepsilon_{\mathrm{o}} & =\varepsilon+\frac{h_{2}}{\rho(0)} \\
=\lambda_{2} & {\left[1-\frac{1}{r}\left(\frac{1-\nu_{2}{ }^{2}}{E_{2} h_{2}}-\frac{h h_{2}}{4 D}\right)\left(1-\frac{1}{\cosh k l}\right)\right.} \\
& \left.-\frac{b \kappa_{2}}{\kappa \cosh k l}\right]
\end{aligned}
$$

と表される。 


\section{2 超磁昰材料に鼠く応力}

基板に超磁歪材料を接着すると，接着剂の収縮により磁歪材 は圧縮力を受ける，磁界零のとき，接着剤の収縮に伴う(せん断 力 $q_{\mathrm{b}}(x)$ による)界面の $x$ 軸方向の変位は, 式(2)之同様に $u_{\mathrm{b} 2}(x)=\frac{1-\nu_{2}{ }^{2}}{b E_{2} h_{2}} \int_{0}^{x} Q_{\mathrm{b}}(\xi) d \xi-\kappa_{2} q_{\mathrm{b}}(x)-\frac{h_{2}}{2} \int_{0}^{x} \frac{d \xi}{\rho_{\mathrm{b}}\langle\xi)}$

である.ここで,

$$
\begin{aligned}
& Q_{\mathrm{b}}(x)=\int_{-1}^{x} q_{\mathrm{b}}(\xi) d \xi \\
& \frac{1}{\rho_{\mathrm{b}}(x)}=-\frac{h}{2 b D} Q_{\mathrm{b}}(x)
\end{aligned}
$$

したがって，接着面のひずみは

$$
\begin{aligned}
\varepsilon_{\mathrm{b}}(x) & =\frac{d u_{\mathrm{b} 2}(x)}{d x} \\
& =\kappa_{2}\left[k_{\mathrm{b}}{ }^{2} \int_{-1}^{x} q_{\mathrm{b}}(\xi) d \xi-\frac{d q_{\mathrm{b}}(x)}{d x}\right]
\end{aligned}
$$

となる．ただし，

$$
k_{\mathrm{b}}^{2}=\frac{h_{2}}{12 b \kappa_{2}}\left(\frac{h_{2}}{D_{2}}+\frac{3 h}{D}\right)
$$

とおいた。

式(9)を得たのと同様にして，境界条件 $q_{\mathrm{b}}(0)=0$ ， $Q_{\mathrm{b}}(l)=0$ を満たす解を求めると.

$$
q_{\mathrm{b}}(x)=\frac{\varepsilon_{\mathrm{b}}(x) \sinh k_{\mathrm{b}} x}{\kappa_{2} k_{\mathrm{b}} \cosh k_{\mathrm{b}} l}
$$

であり, 式(22)から

$$
Q_{\mathrm{b}}(x)=-\frac{\varepsilon_{\mathrm{b}}(x)}{\kappa_{2} k_{\mathrm{b}}{ }^{2}}\left(1-\frac{\cosh k_{\mathrm{b}} x}{\cosh k_{\mathrm{b}} l_{1}}\right)
$$

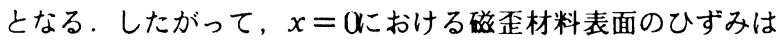

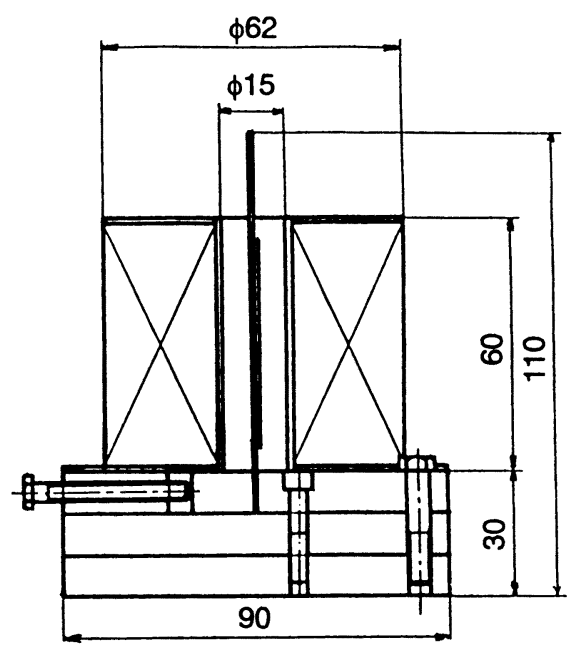

Fig. 3 Schematic view of trial manufactured GMA with laminated type.

$$
\begin{aligned}
& \varepsilon_{\mathrm{ob}}=\varepsilon_{\mathrm{b}}(0)-\frac{h_{2}}{\rho(0)} \\
& \varepsilon_{\mathrm{ob}}=\varepsilon_{\mathrm{b}}(0)\left[1-\frac{h h_{2}}{2 \kappa_{2} b D k_{\mathrm{b}}{ }^{2}}\left(1-\frac{1}{\cosh k_{\mathrm{b}} l_{1}}\right)\right]
\end{aligned}
$$

と表される.これより，磁歪材料表面のひずみ ば, $x=0$ における接着面のひずみ $\varepsilon_{\mathrm{b}}=\varepsilon_{\mathrm{b}}(0)$ を求めるこ
とができる

接着剤の収縮に伴って磁歪材に㗢く応力は

$$
\begin{aligned}
& \sigma_{\mathrm{b}}(x)=\frac{Q_{\mathrm{b}}(x)}{b h_{2}}-\frac{6 M_{\mathrm{b} 2}(x)}{b h_{2}{ }^{2}} \\
& =\frac{\varepsilon_{\mathrm{b}}(x)}{\kappa_{2} b h_{2} k_{\mathrm{b}}{ }^{2}}\left(1+\frac{3 D_{2} h}{D h_{2}}\right)\left(1-\frac{\cosh k_{\mathrm{b}} x}{\cosh k_{\mathrm{b}} l_{1}}\right)
\end{aligned}
$$

である. また，磁歪によって磁歪材が基板から受ける応力も同 様にして

$$
\sigma(x)=\frac{\lambda_{2}}{\kappa h_{2} k^{2}}\left(1+\frac{3 h D_{2}}{h_{2} D}\right)\left(1-\frac{\cosh k x}{\cosh k l_{1}}\right)
$$

であるから，印加磁界の下で磁歪材に㗢く全応力は

$$
\begin{aligned}
\sigma_{\mathrm{tota} 1}(x) & =\sigma_{\mathrm{b}}(x)+\sigma(x) \\
& =\frac{1}{h_{2}}\left(1+\frac{3 h D_{2}}{h_{2} D}\right)\left[\frac{\varepsilon_{\mathrm{b}}(x)}{\kappa_{2} b k_{\mathrm{b}}^{2}}\left(1-\frac{\cosh k_{\mathrm{b}} x}{\cosh k_{\mathrm{b}} l_{1}}\right)\right. \\
& \left.+\frac{\lambda_{2}}{\kappa k^{2}}\left(1-\frac{\cosh k x}{\cosh k l_{1}}\right)\right]
\end{aligned}
$$

となる．したがって， $x=0$ において磁歪材に働く全応力 $\sigma_{\text {total } 1}$ は

$$
\begin{aligned}
\sigma_{\mathrm{tota} 1}= & \frac{1}{h_{2}}\left(1+\frac{3 h D_{2}}{h_{2} D}\right)\left[\frac{\varepsilon_{\mathrm{b}}}{\kappa_{2} b k_{\mathrm{b}}^{2}}\left(1-\frac{1}{\cosh k_{\mathrm{b}} l_{1}}\right)\right. \\
& \left.+\frac{\lambda_{2}}{\kappa k^{2}}\left(1-\frac{1}{\cosh k_{1}}\right)\right]
\end{aligned}
$$

と表される。

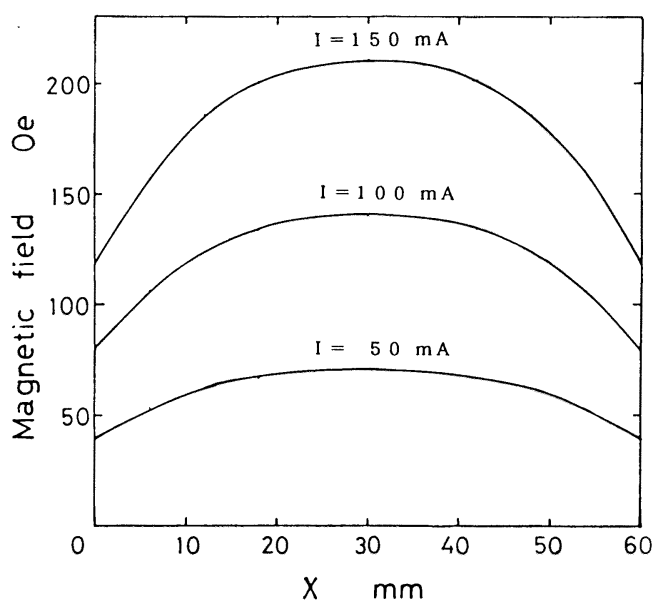

Fig. 4 Magnetic field of actuator with solenoid coil

\section{3. 実験方法}

本研究で試作した積首型超磁歪アクチュエータの断面図をFi g. 3に示す. アクチュエータは, ソレノイドコイルにより発生す る磁界で駆動する．アクチュエータを駆動する多層型のソレノ イドコイルの設計は既報(1)に従っている. 円筒形のアクチュエ 一夕はFig. 4に示す如く, 内半径 $a_{1}$, 外半径 $a_{2}$, 円筒長さ $l$ ，巻数 $N$ ，印加電流 $i$ とすると, ソレノイドコイルの磁界 の強さH は, 次式となる(1)

$$
\begin{aligned}
H= & \frac{N i}{2 l\left(a_{2}-a_{1}\right)}\left\{x \log \frac{a_{2}+\sqrt{a_{2}{ }^{2}+x^{2}}}{a_{1}+\sqrt{a_{1}{ }^{2}+x^{2}}}\right. \\
& \left.+(l-x) \log \frac{a_{2}+\sqrt{a_{2}{ }^{2}+(l-x)^{2}}}{a_{1}+\sqrt{a_{1}{ }^{2}+(l-x)^{2}}}\right\}
\end{aligned}
$$




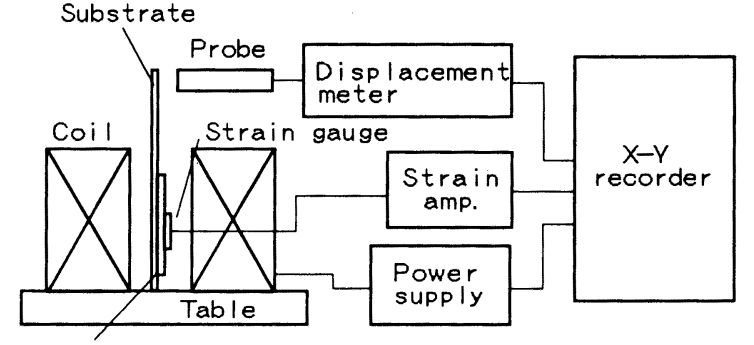

G.M.material

Fig. 5 The displacement characteristics measuring circuit of GMA

本研究で使用したコイルのパラメー夕は， $a_{1}=15 \mathrm{~mm}, a_{2}$ $=62 \mathrm{~mm}, l=60 \mathrm{~mm}$, 巻数 8000 回, 線密度 $71.3 \%$,

線長 $967.6 \mathrm{~m}$, 抵抗 $138.5 \Omega$ である.

得られた結果は, Fig. 4に示すような磁界分布となった。 ソレノイドコイルは, 印加電流 $100 \mathrm{~mA}$ 対して中央部で 1200 e の磁界を発生する．本実験使用の超磁歪材料は，全長に亘って 均一の磁歪が与えられることがわかる

超磁歪材料として厚さ0.3m拈よび0. $5 \mathrm{~mm} の \mathrm{~T} \mathrm{~b}_{0.27} \mathrm{D} \mathrm{y}_{0.73} \mathrm{Fe}_{1}$ 。を用い, S U S 316ステンレス鋼(厚さ0. $1 \mathrm{~mm}$ )の基板に接着して, Fig. 5のような測定回路で変位とひずみを測定した.

測定には, 変位y total を非接触式の静電容量型プローブ, ひずみ $\varepsilon_{0}$ を磁歪材に接着したひずみゲージにより検出し， $X ー Y$ レコーダに印加電流と共に記録した．接着剤による影響 を考虑するため, 初め磁歪材にひずみゲージを接着し，その後 磁歪材を基板に接着した。

\section{4. 結果およひ考宾}

磁歪材表面のひずみ $\varepsilon_{0}$ とアクチュエー夕の変位 $y_{t o t a l}$ の 印加磁界依存性の測定結果を，基板に超磁歪材を接着した場合 についてFig.6に示す．超磁歪ロッドにおけるひずみあるいは変 位の磁界依存性と同様に，ヒステリシスループを描いている。

変位 $y_{t o t a l}$ の測定結果から式(17)により求めた磁歪 $\lambda_{2}$ を 用いて, 式(20)より測定面のひずみの計算結果と測定結果を比 較したものをFig. 7に示す．測定值は，測定開始時点のひずみを 零としている．解析は単純化したモデルについて行っているこ とを考虑すると，両者はよく一致しているといえる．

次に, 式(17)により求めた磁歪 $\lambda_{2}$ と, 磁歪材薄板のみで測定 した磁歪を比較した，結果をFig. 8に示す．低磁界のときには， 磁歪材のみの場合より基板に接着した場合の方が磁歪が大きく， 超磁歪材特有のジャンプ現象 (5) が見られる.ある程度磁界が大 きくなると, 基板から受ける圧縮力の增加により, 磁歪材のみ の場合に比へ磁歪は低下する．このとき磁歪材に働く応力は式 （29）で表され，磁界の增加に対する応力の変化はFig.9のように なる．磁界の增加とともに応力は增加する．

$\mathrm{H}=0$ での応力値は，接着剤の収縮による圧縮応力であり，磁歪 材を基板に接着したことによって生じた磁歪材表面のひずみ $\varepsilon_{o b}$ の測定値を用いて，式(27)から得られる.

最後に, 基板と磁歪材の厚さによる変位 $y_{\text {total }}$ の相違をFi g. 10に示す.ここでは, $l_{1}=5 \mathrm{~mm}, l_{2}=45 \mathrm{~mm}, \lambda_{2}=100 \mathrm{pp}$ mとして, 式(17)により計算した. 磁歪材厚さ $h_{2}$ が一定のとき, 基板の厚さ $h_{1}$ に関して変位は上に凸の関数となり, 変位が最 大となる基板厚さが存在する．そのときの基板の厚さは, 磁歪
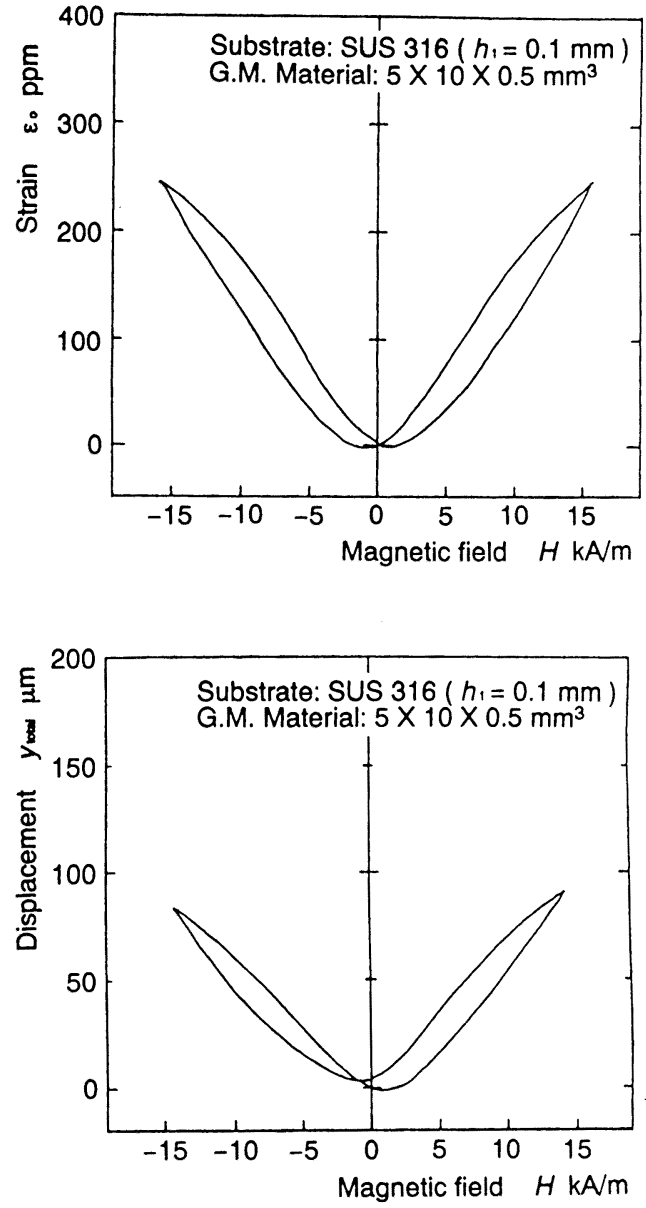

Fig. 6 Strain $\varepsilon_{0}$ on G.M. material and actuator displacement $y_{\text {total }}$ due to magnetic field.

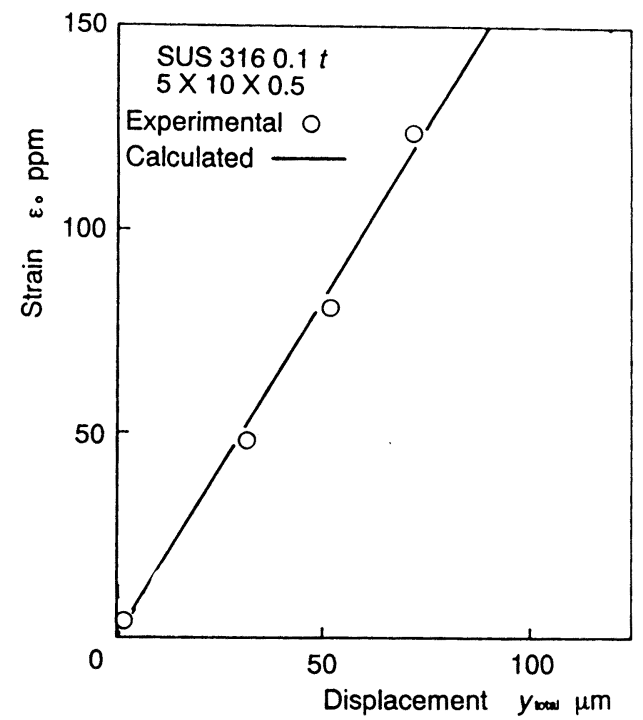

Fig. 7 Comparison of calculated and experimental values for strain $\varepsilon_{0}$ on G.M. material and actuator displacement $y_{\text {total }}$. 


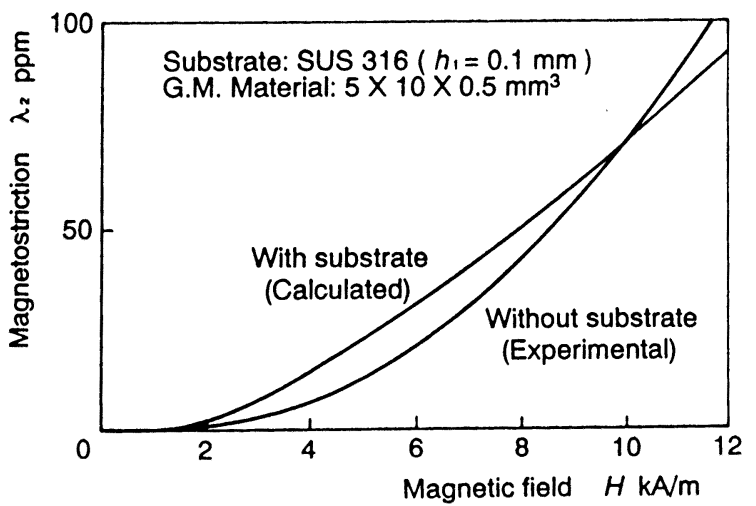

Fig. 8 Comparison of calculated magnetostriction $\lambda_{2}$ in ease of G. M. with substrate (adhesive agent) and experimental value without substrate.

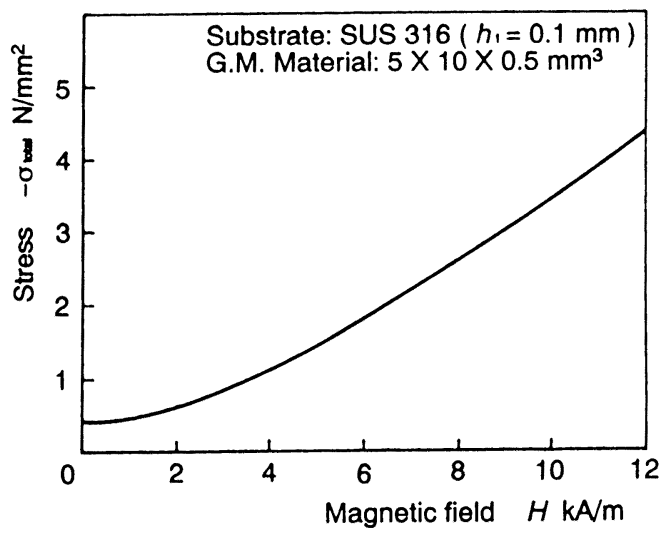

Fig. 9 Acting stress to G.M. material of the laminated type actuator by adhesive agent.

材の厚さの約 $1 / 2$ である. それ以上基板が厚くなると, 磁歪材が 伸びようとしても基板が曲がりにくく，したがって変位は小さ くなる，逆に薄くなると，基板が磁歪材に引っ張られて伸びや すくなり，やはり変位は小さくなる．このことは, アクチュ工 一夕の最適設計上考虑すべき重要なポイントである.

以上により，接着剂接合による高周波数対応の積層型超磁歪 アクチュエータが設計できる，既に，森ら (3) は，超磁歪板厚さ 0. $4 \mathrm{~mm} て ゙ ， f_{\mathrm{c}}=350 \mathrm{khz}$ 迄実用可能であることを示しているので， 本研究は，これら積層型アクチュエー夕設計に適用できる。

\section{5. 䊅言}

積首型超磁歪アクチュエータを試作し，その静的特性を検討 するために，変位と応力の理論解析を行った，得られた結論を 要約すると, 以下のようになる.

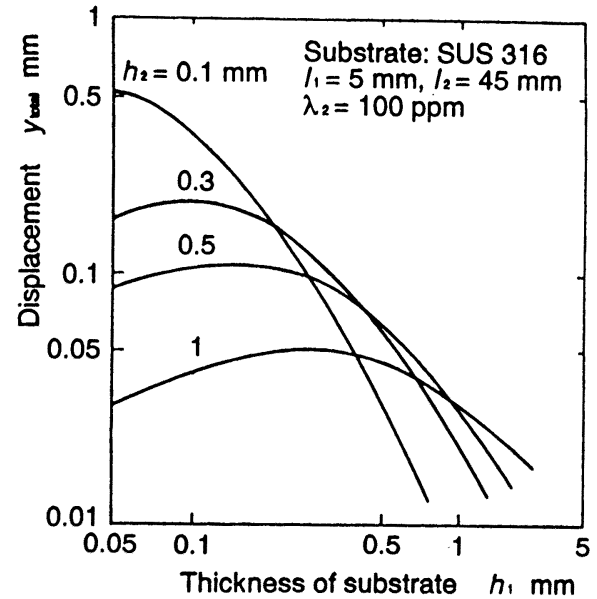

Fig. 10 Comparison of displacement $y_{\text {total }}$ as function of thickness $h_{1}, h_{2}$.

（1）基板の変位（たわみ）から超磁歪材料の磁歪を求める理論式 を導いた。

（2）超磁歪材に働く応力の理論式を，接着剤の収縮も考虑して導 いた.

（3）実験結果との比較を行い, それらの妥当性, 有用性を確認し た。

（4)積層する際，基板の変位（たわみ）を最大にする磁歪材と基 板の厚さの組み合わせが存在する．このことは, アクチュ工 一夕の最適設計上重要である.

\section{謝辞}

本研究遂行にあたり，実験面で多大のご協力を賜った(株)日 立製作所 日立研究所 笹山隆生研究部長ならびに嶋田 智研究 主任, T D K (株)基礎材料研究所 森 輝夫課長ならびに岡本重 夫氏に深甚の謝意を表します．また，本研究は文部省科学研究 費(02805016)によることを付記し，感謝致します．

\section{文献}

（1）たとえば，H.Eda, E. Ohmura, M. Sahashi and T.Kobayashi, Ultra-P recise Machine Tool Equipped with a Giant Magnetostriction Actuator -Development of New Materials, $\mathrm{Tb}_{\mathrm{x}} \mathrm{Dy_{1- \textrm {x } }}\left(\mathrm{Fe}_{\mathrm{v}}\right.$

$\left.\mathrm{Mn}_{1-\mathrm{v}}\right)_{\mathrm{n}}$ and Their Application, Annals of the C I R P, 41-1(1992)421.

または，江田他多数，超磁歪材料のアクチュIー㚈の応用 分科会 報告書 精密工学会(1994.2)5

(2) T. Fukuda, Giant Magnetostrictive Alloy Appli cations to Micro Mobile Robot as a Micro Actua - tor without Power Supply Cables, Proc., IEEE Micro Electro Mechanical Systems. (1991)210.

（3）森 輝夫, 精密工学会超磁歪材料のアクチュエータへの応 用に関する研究分科会資料, H2-4-03，(1990).8

(4) E. Shuhir, Stresses in Bi-Metal Thermostats, J . Appl. Mech., 53. 9(1986)1032.

(5) A. E. Clark, J.P. Teter, and O. D. McMasters, Magnetostriction " J umps" in Twinned $\mathrm{Tb}_{0,3} \mathrm{D} \mathrm{y}_{0}$ $\mathrm{Fe}_{1, \theta}$, J . Appl. Phys., 63-8(1988)3910. 